\title{
Articles
}

\section{"Happy, just talking, talking, talking": Community strengthening through mobile phone based peer support among refugee women}

Dennis Wollersheim

\section{Lee Koh}

Rae Walker

Pranee Liamputtong

\author{
La Trobe University, Australia \\ Corresponding Author. \\ d.wollersheim@1atrobe.edu.au \\ La Trobe University, Australia \\ 1.koh@latrobe.edu.au \\ La Trobe University, Australia \\ r.walker@latrobe.edu.au \\ Western Sydney University, Australia \\ P.Liamputtong@westernsydney.edu.au
}

Resettled refugees face lack of information and support, due to disrupted community and cultural mismatch. In this context, we provided 111 refugee women peer support training and a restricteddial unlimited-call mobile phone in Melbourne, Australia. We gathered demographic, phone call, pre and post intervention questionnaires, and interview data.

The provided resources synergised with existing resources such as social capital and information demand, resulting in changes to resource allocation and social processes, such as economic resource reallocation, information sharing, personal agency, and social support. These changes impacted areas such as employment, education, transportation and domestic violence, leading to improved individual lives and community functioning.

Wollersheim, D., Koh, L., Walker, R., Liamputtong, P. (2017). 'Happy, just talking, talking, talking: community strengthening through mobile phone based peer support among refugee women. The Journal of Community Informatics, 13(1), 50-71.

Date submitted: 2016-04-07. Date accepted: 2017-01-08.

Copyright (C), 2016 (the authors as stated). Licensed under the Creative Commons AttributionNonCommercial-ShareAlike 2.5. Available at: www.ci-journal.net/index.php/ciej/article/view/1300 


\section{Introduction}

Prilleltensky (2008:359) characterises migrant wellbeing as a "multilevel, dynamic, and value dependent phenomenon". This is particularly true for refugee migrants, whose problems are complex, systemic and have structural components outside their control (Stewart et al, 2014; Tempany, 2009). In this context, we introduced a free-call mobile phone based peer support program for 111 refugee women in Melbourne Australia to facilitate their resettlement process. In this paper, we describe how the program functioned at the systems setting level.

Refugees are at higher risk of poor health, poor economic prospects, unemployment, and low education. Refugees experience trauma from stressors such as grief and loss, loss of cultural identity, economic and social disadvantage and experiences of violence (Cislo et al, 2010; Correa-Valez et al, 2010; Dow, 2011; Ngum Chi Watts et al, 2014; Beadle, 2014). Refugee problems are also structural. Refugee women are multiply marginalised and subject to racism, sexism, and classism (Goodkind and Deacon, 2004), which leads to the women internalising the oppressive messages and then perpetuating them to self and peers (David, 2013). For example, women's internalised oppression generally dictates that refugee women have lower personal resource consumption (including education and money), and reduced access to the public sphere (leading to lower exposure to and practice of the dominant language).

Typically, pre-migration, refugees to Australia lived communally. Refugee migration damages community, which is integral to their lives. Refugees arrive geographically isolated from family and potential local peers. Their ability to grow community is impeded by linguistic isolation from neighbours and geographic isolation from linguistic peers, leading to social isolation and lack of support (Schweitzer et al, 2006; Tempany, 2009). Programs designed to counter such disadvantage tend to be optimised for mainstream individualist culture, while many refugee traditional cultures are collectivist or family-centred (Triandis, 1996). This situation argues for an empowerment based solution, where refugees can use their personal agency to fulfil their particular needs (Rappaport, 1987).

In Australia, information is increasingly available and important (ABS, 1999), making education essential. Refugees often have low initial education, more so for women (Goodkind and Deacon, 2004), and this, combined with ongoing oppression, leads to limited capacity to obtain and use information, leading to less ability to use Australian resources. Internet information is inaccessible to many refugees due to internet information largely being in written English.

We theorised that mobile phones, combined with peer support, can be used by refugee communities to obtain and share valuable quotidian information, leading to mutual empowerment and relationship strengthening. From our experience, a best case information resource for refugees would have the following characteristics: a) be in an understandable language (both in level and vocabulary), b) contain knowledge 
appropriate for questions asked, c) be physically accessible, d) be at the correct level of detail, and e) have an accessible emotional tone.

A community of refugee peers connected using mobile phones can more likely provide such a resource, and refugees themselves would use this resource, due to their information and support deficit. Flow on effects would include emotional support and social capital (Fisher, 2004), and the increased practical support and access to information, given to women often in the centre of their families, would lead to increased familial and community wellbeing.

\section{Theoretical framework}

The intervention used in this study was based on a technology, mobile phones, and social skills training in peer support, for refugee women. The intervention was designed to shift the interaction patterns of the participating women into a more constructive state (Foster-Fishman, Nowell \& Yang, 2007), leading to increased settlement success and overall community health. Tseng and Seidman's (2007) framework, outlined in Figure 1 , is particularly appropriate for analysing socio-technical interventions such as that used in this project.

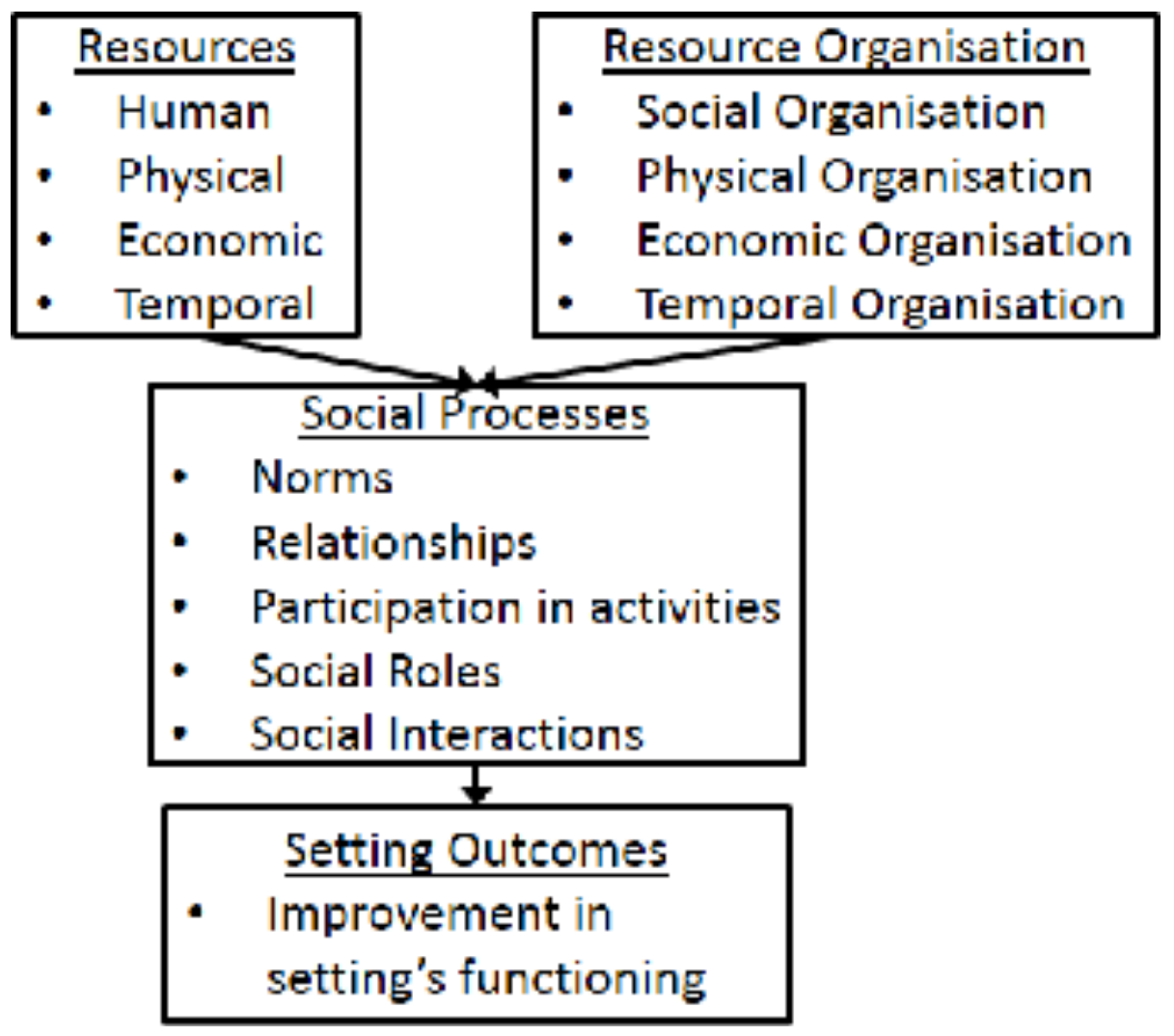

Figure 1 - A systems framework for understanding social settings, adapted from Tseng and Seidman (2007)

Social system components are often considered in two aspects: system structure, and social processes. The latter consists of 'actions and operations' which express social 
system qualities (Kelly et al, 2000:139). In Tseng and Seidman's (2007) framework, a system's structural features, including resources and their organisation, strongly influence the social processes within the setting and the experiences and actions of participants. The elements in the model have bi-directional influences but are represented here as unidirectional to emphasise the intervention design logic (Tseng \& Seidman, 2007).

\section{Resources}

Resource availability and quality, within a system or setting, are important, but alone they are insufficient to create meaningful outcomes (Tseng \& Seidman, 2007). Their relationships to outcomes are mediated by resource organisation and social processes. Resource categories include human, physical, economic and temporal. Of particular importance are human resources, which are the personal qualities, skills and information that individuals could offer other system participants. These can also be described as 'personal resource potentials' (Kelly et al, 2000:136), which emphasises that individuals may be able to express personal qualities in a context that enacts supportive norms and values. This emphasis separates personal resource potential from simply networking.

Social system resources are 'groups, procedures or events that influence the development of social systems' (Kelly et al, 2000:137). According to Kelly et al. (2000:137), 'social system resources include not only information, money and influence but also traditions, customs and observances that facilitate feelings of integration and being part of a social system'.

\section{Resource organisation}

Resource organisation influences people's resource engagement. Social system resource organisation can promote the development of individuals as well as the relationships with other social systems, as long as there are norms and values that encourage such activities. This intervention, through a mobile phone technological resource organisation, facilitated group member relationships. Peer support training, and its application in daily life, created a social system resource that could be used in diverse contexts.

Physical resource organisation and social resource organisation are often related. In Australian communities, many physical resources such as cars, housing and household related equipment are held privately. For refugee women on low incomes, accessing such resources depends on them being able to access publicly provided resources, or building relationships with resource owners.

Economic resource organisation refers to the distribution of funds within a system. Distribution of economic resources can occur through welfare, paid work or private industry such as tailoring or cleaning services. The mobile phones and peer support relationships have the potential to influence the women's access to economic resources in much the same way as they do with physical resources. 


\section{Social processes}

Social processes are 'ongoing transactions between two or more people or groups ... in a setting' (Tseng \& Seidman, 2007:219), and are influenced by people's roles. They involve a 'constant stream of action, wherein transactions are repeated, behaviours are recalibrated based on feedback, and patterns are reinforced over time' (Tseng \& Seidman, 2007:219). Tseng and Seidman (2007) suggest that the social processes associated with positive system level outcomes are norms, relationships and activity participation.

Social norms (including attitudes, values and beliefs) regulate and foster behaviours within a system. When values, beliefs and attitudes are shared, 'they create a dominant normative context that determines the practices and functions of a system or subsystem' (Foster-Fishman, Nowell, Yang, 2007:205). Shared experience helps people to learn the norms, the 'appropriate and acceptable' behaviours in a setting (Kelly et al, 2000:144)

Relationships are influenced by both social roles, such as that of parent or child, as well as the actual interactions people have with other individuals and networks (Tseng \& Seidman, 2007). Kelly et al. (2000) argue that there are four key relationship processes: reciprocity, networking, boundary spanning and adaptation. Reciprocity refers to the conscious give and take within relationships and a commitment to being mutually helpful. Personal and social system resources come into existence when reciprocity becomes a system norm. Networking is more superficial, referring to efforts to establish communication with other participants in a system, or other systems. Boundary spanning refers to establishing relationships with members of other systems in order to access or exchange resources (Kelly et al, 2000). Finally, adaptation refers to the processes people create to respond to the demands within their own or external systems, to 'develop competencies in individuals and resources of the social system' (Kelly et al, 2000:142).

\section{Methods}

The study used mixed methods to examine the community and individual level effects of a mobile phone based peer support program for women refugees in south-eastern Melbourne, Australia, 2010-2012.

\section{Intervention design}

We designed the intervention to maximise community-wide effects, choosing the communities based on our ability to recruit effective community leaders, and on the number of recently arrived refugee membership in the target geographic area. From the Nuer (South Sudanese), Dari (Afghan), Burmese Buddhist (hereafter B1), and Burmese Moslem (hereafter B2) communities, we recruited leaders who were widely respected, had good community-wide relationships, and who could think well about their community. 


\section{Recruitment}

Participants were initially invited by their respective community leaders to an information session, based on the leader's assessment of the participant's ability to both make use of the resource offered and possession of sufficient resource so that they were able to listen and offer help. We recruited participants who were already leading in the community, both so that they could become more effective in increasing overall community power and information, and to provide the system setting with sufficient resource to support and sustain itself. At the information session we explained the study and distributed participant information sheets, in both English and heritage languages. Potential participants were given opportunities to seek clarification before signing the informed consent for participation. A snowball sampling technique was also used, where the initial participant groups invited people with whom they had relationships (Liamputtong, 2013). This action further dispersed the resource allocation function onto participants, fostering empowerment.

One hundred and eleven women were recruited over six months, including 44 Nuer, 31 Dari, and 25 and 11 into the B1 and B2 groups respectively. Table 1 presents the participant demographics.

Table 1 - Participant demographics at the commencement of the program. Note, standard deviations are in brackets.

\begin{tabular}{|c|c|c|c|c|c|c|c|c|}
\hline Group & $\mathbf{N}$ & $\begin{array}{c}\text { Mean \# } \\
\text { of adults } \\
\text { in house }\end{array}$ & $\begin{array}{l}\% \text { of } \\
\text { mo- } \\
\text { thers } \\
\text { with } \\
\text { hus- } \\
\text { band } \\
\text { present } \\
\text { in } \\
\text { Austra- } \\
\text { lia }\end{array}$ & $\begin{array}{c}\text { Mean \# } \\
\text { chil- } \\
\text { dren } \\
\text { per } \\
\text { mother }\end{array}$ & $\begin{array}{l}\text { Mean } \\
\text { age in } \\
\text { years }\end{array}$ & $\begin{array}{c}\text { Mean } \\
\text { years in } \\
\text { Australia }\end{array}$ & $\begin{array}{c}\text { Had } \\
\text { mobile } \\
\text { phone } \\
\text { at pro- } \\
\text { gram } \\
\text { start } \\
\%\end{array}$ & $\begin{array}{c}\text { Emplo } \\
\text { yed at } \\
\text { pro- } \\
\text { gram } \\
\text { start } \\
\%\end{array}$ \\
\hline $\begin{array}{l}\text { Burmese } 1 \\
\text { (B1) }\end{array}$ & 25 & $3.83(1.5)$ & $75 \%$ & $\begin{array}{r}3.1 \\
(1.65)\end{array}$ & $\begin{array}{r}35.7 \\
(13.5)\end{array}$ & $2.88(1.85)$ & $62 \%$ & $4 \%$ \\
\hline $\begin{array}{l}\text { Burmese } 2 \\
\text { (B2) }\end{array}$ & 11 & $\begin{array}{r}4.33 \\
(1.94)\end{array}$ & $100 \%$ & $\begin{array}{r}4.2 \\
(2.05)\end{array}$ & $\begin{array}{r}39.0 \\
(12.9)\end{array}$ & $4.00(1.00)$ & $30 \%$ & $0 \%$ \\
\hline $\begin{array}{l}\text { Dari } \\
\text { (Afghan) }\end{array}$ & 31 & $\begin{array}{r}4.14 \\
(1.41)\end{array}$ & $72 \%$ & $\begin{array}{r}3.5 \\
(1.89)\end{array}$ & $\begin{array}{r}33.2 \\
(13.1)\end{array}$ & $4.19(2.09)$ & $74 \%$ & $0 \%$ \\
\hline $\begin{array}{l}\text { Nuer } \\
\text { (South } \\
\text { Sudanese) }\end{array}$ & 44 & $\begin{array}{r}3.08 \\
(1.51)\end{array}$ & $50 \%$ & $\begin{array}{r}4.5 \\
(1.99)\end{array}$ & $\begin{array}{r}36.7 \\
(11.0)\end{array}$ & $6.81(2.65)$ & $93 \%$ & $9 \%$ \\
\hline
\end{tabular}

Participants were offered two resources: peer support training and free mobile communication. The purpose of the peer support training sessions were to build relationships between members of the participating communities, and to foster and 
make evident personal resource potentials. The sessions were structured to be single heritage groups with 9-15 members, meeting weekly for the first six weeks and then bimonthly for five meetings. The group format was designed to deepen community relationships by increasing communication skills and increasing trust.

The training sessions aimed be highly structured, allowing for a safe space to practice intimate communication and trust. Each group started with reporting of new and good events. Then the women "swapped time", taking turns to talk and listen for durations of three to five minutes each. This was followed by group wide communication, where each member would address the chosen topic, in turns, without interruption. Topics were selected using a strength-based, assets model designed to focus the women's attention on their own strengths, and the positives in their lives (Smith, 2006), and included "goals and aspirations"; "educational successes"; "personal pride"; and "successes in life in Australia". Additional topics were chosen opportunistically, based on current events (eg South Sudanese independence). Detailed group functioning is more fully outlined in Liamputtong et al (2015).

Additionally, in the first and second training sessions, the women filled in the pre and post-intervention questionnaires, detailed below. In the third training session, each woman was given a mobile phone with the following unlimited free-call numbers on speed-dial:

- Intragroup numbers: peer support group members from the same community (all heritage culture links);

- Landline numbers: five participant-chosen Australian landline including home phone numbers, or overseas numbers from selected countries (largely heritage culture links); and

- Service numbers: Translating and Interpreting Service (TIS), four participantchosen service provider numbers, and researchers (LK \& DW) who facilitated the peer support groups (all host culture links).

This initial group structure allowed adjustments in response to community leader advice and/or participant preference, resulting in alterations to scheduling, format, and group composition. The responsiveness further empowered participants. For example, one Nuer group was cancelled after the community leader informed us that the mother of a group member had died, and all the group members would be at the grieving person's house at the time of the group. The leader advised the group facilitators to pay our respects at the home of the bereaved. We did as advised, rescheduled the group and visited the bereaved household. This action fostered the idea that all the relationships, even those with researchers, were relationships between peers.

Overall, the Dari group was exceptional, in that the participants did not have wide preexisting relationships. Due to member demand, in place of the bi-monthly meetings, we combined the three Dari groups into one, giving more opportunities for relationships to develop. This larger group met monthly, with 10-18 participants attending. For this group, we arranged childcare, transport, and a post-group meal. 
Peer support group activities ran for 12 months. Groups had staggered start times, but the whole programme ran from 2010 to 2012. Some women did not attend all the training sessions, and/or stopped using their phones, but no one formally withdrew from the program. In our qualitative component (see below), we also interviewed women who made relatively fewer calls.

\section{Mobile phone plan setup}

A corporate contract with a mobile phone service provider enabled the program to make relatively inexpensive flat-rate calls to both intragroup and 10 fixed landline phone numbers. The fixed landlines were redirected via Voice over Internet Protocol (VoIP), on a per-participant basis, to nine participant chosen numbers, and the TIS.

The cost of the phone calling resource was $\$ A U$ 29,974, which included both the mobile phone and VoIP infrastructure cost for the six-month recruitment and 12-month intervention period. The actual cost would have been $\$ A U 488,210$ if calls were made using standard prepaid rates.

At the end of the program, calls on the network stopped, but the phones continued to be operational.

\section{Data collection}

Outgoing phone calls made by the women were recorded automatically in a call log that captured the time, duration and destination of calls. Only intragroup incoming calls could be recorded. Participants filled in pre and post-intervention questionnaires, at program start and end, which measured quality of life (WHOQoL), self-esteem (Rosenberg's Self-esteem Scale), self-efficacy (Efficacy Scale) and friendship (Friendship Scale). At the first session, participants also filled a demographic questionnaire. All the questionnaires had gone through a vigorous process of forward and backward translation from English into Nuer, Burmese and Dari. The recruiting community leader and several respected members of each community were consulted to ensure that the questionnaires were culturally appropriate for the community. The questionnaires were administered with the assistance of the bilingual community leaders and/or interpreters. Only the demographic and call data are reported here. The results of the pre and post-intervention questionnaires are complex and appropriately discussed in detail elsewhere.

\section{Interviews}

Participants indicated yes/no, on the consent form, to a request for an audio-taped interview, and interviewees were selected among participants who had provided an affirmative answer. The researchers verbally reconfirmed consent with the participants at the time of the interview. Unless language was a barrier and participants had to be invited through the relevant interpreters, interview requests were made directly by the researchers. 
The 29 interview participants included women from each community, who were selected based on their diversity of phone calling patterns, e.g. people with short, long, few, or many calls. The 60-90-min interviews took place in the participants' homes, and were conducted through an interpreter except for two participants who were proficient in English. During the interview, the women were asked about their experiences with the program, the differences in their lives and relationships as a result of the program as well as their call usage patterns. The transcripts of these audio-recorded interviews provided the qualitative data for the project.

\section{Data analysis}

Demographic data was analysed using descriptive statistics. Call log data was analysed according to the three categories of free call numbers programmed into each phone.

- Landline / intragroup / service call duration: the average length of calls

- Landline / intragroup / service call frequency: the number of calls a person made

- Intragroup call breadth: the number of participants (from the same community) who each participant called

Qualitative data was analysed using thematic methods (Liamputtong, 2013), where potential categories were identified from an initial reading of the interview transcripts. The categories were then aggregated, in an iterative and collaborative process, into a set of defined core and related themes, facilitated by the NVivo software. The process was error checked by two researchers (LK and RW) who discussed and resolved differences from the coding of three initial transcripts.

\section{Ethics}

Ethics approval for the project was granted by the Faculty Human Ethics Committee, La Trobe University. We used fictitious names in presenting the narratives of the women to preserve their confidentiality. Verbatim quotes are also minimally edited for ease of reading.

\section{Findings}

In this section, we show the program's health promotion effects on the refugee communities through four interlinked aspects: resources, resource organisation, social processes, and social outcomes. We found that the program resources acted as catalysts, facilitating the mobilisation and reorganisation of other nascent pre-existing resources. This enhanced social processes, and led to settings level social outcomes, as summarised in Figure 2. 


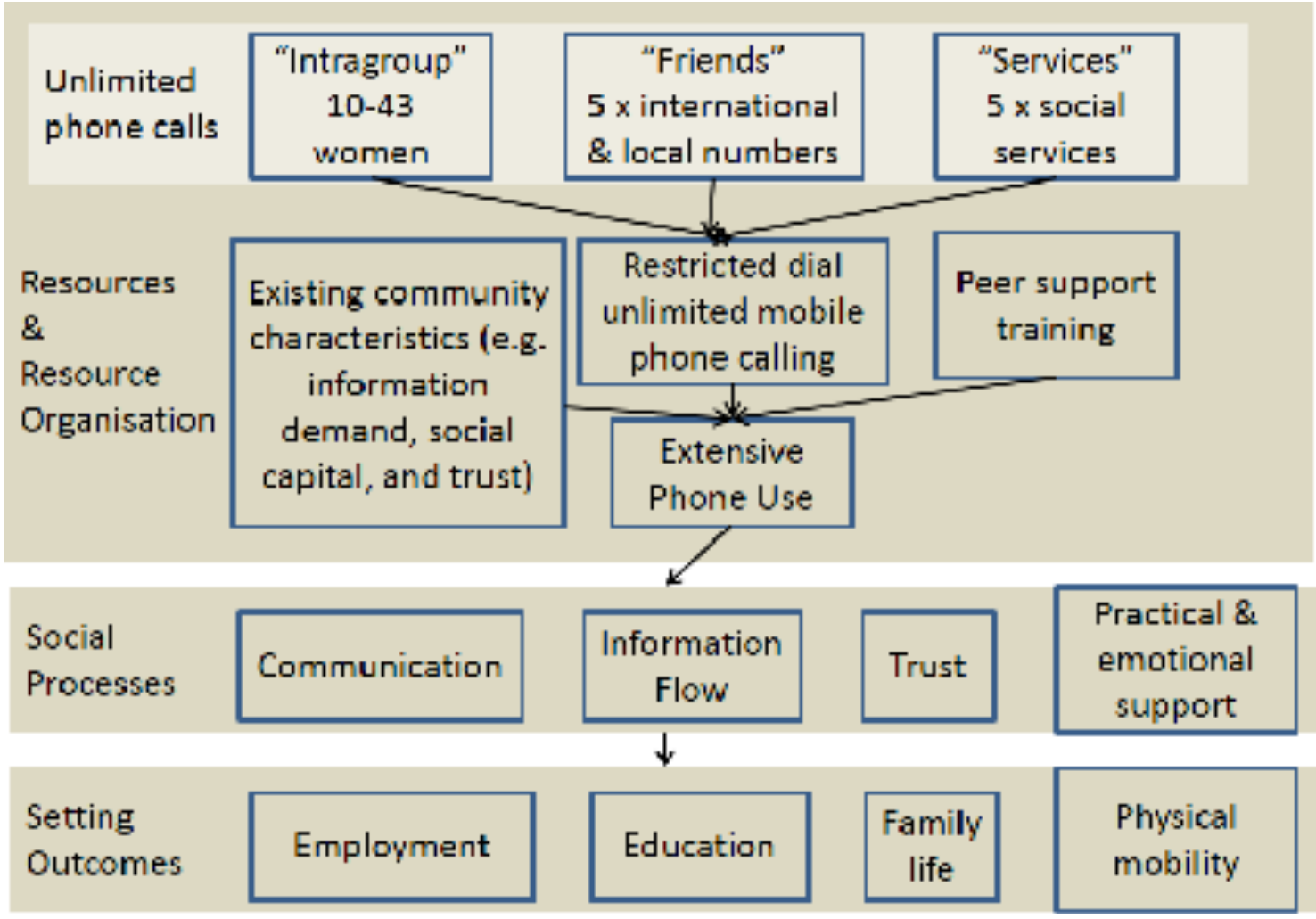

Figure 2 - Community level program effect summary

\section{Resources}

The intervention supplied peer support training which potentiated the mobile phones resource.

Without the meetings, the mobile wouldn't be helpful. Because if we didn't see each other, we didn't meet each other, so we wouldn't get relationship and get together. (Farhana, Dari)

While the peer support groups had a common structure to practice interpersonal intimacy and build trust, the dynamics of each community's groups differed due to preexisting community dynamics and relationships. For example, when the women lacked pre-existing relationships, the structured practice was more effective, because existing habitual communication patterns did not interfere. When participants had pre-existing relationships, the group practice allowed the relationships to operate at a different level.

Prior to the program, the women generally had low mobile phone resource, either having no phone, or more often, having a phone that could not make outgoing calls due to having zero call credits. The latter situation disempowered the women, allowing communication solely at another's behest.

This original resource deficit enhanced the intervention, because we converted participant's mobile phone functionality from "intermittently useful" to "reliable", which is qualitatively more useful than merely a lower phone bill. Farhana describes the difference: 
Before having the telephone, I might call my friends once a day or two, even two days ... But after having this phone we made lots of phone calls. ... it is totally different before having the phone and after (Farhana, Dari)

The phone resource was used widely to sustain communication channels, and often shared with others. For example, it was used by the children to call other families; left with the babysitter while the mother went out; and given to a son who had soccer training.

Table 2 shows actual phone use. Each group had distinctive calling patterns, seemingly related to two factors: pre-existing relationships and familiarity with mobiles. The Nuer and B1 groups had wide pre-existing relationships and much mobile familiarity. Here, we see large (many intragroup calls) and broad (to many different community members) phone usage, with group members reporting both long relationship-sustaining social chats and more purposive short calls.

In contrast, B2 group members also had strong pre-existing relationships, but lacked mobile phone familiarity. This led to broad phone usage, with calls of limited duration. B2 group members reported using the phone to coordinate, but then meeting face-toface socially.

The Dari group had an opposite pattern, arising from low levels of pre-existing relationships, but high mobile phone familiarity. As a result, their phone communication was narrow, albeit with long duration calls among people with pre-existing relationships, such as their chosen extra-group phone numbers.

Table 2 - Mobile phone call statistics $(\mathrm{SD}=$ standard deviation)

\begin{tabular}{|c|c|c|c|c|c|}
\hline \multicolumn{2}{|c|}{$\begin{array}{l}\text { Group Name } \\
\text { (Number of members) }\end{array}$} & $\begin{array}{r}\text { Burmese } \\
1\end{array}$ & $\begin{array}{r}\text { Burmese } \\
2\end{array}$ & $\begin{array}{r}\text { Dari } \\
(31)\end{array}$ & $\begin{array}{r}\text { Nuer } \\
(44)\end{array}$ \\
\hline \multirow[t]{2}{*}{ Intragroup calls } & $\begin{array}{l}\text { Mean Individual Call } \\
\text { Length minutes (SD) }\end{array}$ & $\begin{array}{r}4.45 \\
(11.15)\end{array}$ & $\begin{array}{r}3.17 \\
(8.57)\end{array}$ & $\begin{array}{l}2.24 \\
(5.7)\end{array}$ & $\begin{array}{r}5.72 \\
(12.24)\end{array}$ \\
\hline & $\begin{array}{l}\text { Mean total call } \\
\text { volume Minutes / } \\
\text { person / week (SD) }\end{array}$ & $\begin{array}{r}83.48 \\
(97.21)\end{array}$ & $\begin{array}{r}18.8 \\
(25.51)\end{array}$ & $\begin{array}{r}15.14 \\
(17.63 \\
)\end{array}$ & $\begin{array}{r}104.48 \\
(101.16)\end{array}$ \\
\hline \multirow[t]{2}{*}{ Overseas Calls } & $\begin{array}{l}\text { Mean Individual Call } \\
\text { Length in Minutes } \\
\text { (SD }\end{array}$ & $\begin{array}{r}10.21 \\
(19.94)\end{array}$ & $\begin{array}{r}6.28 \\
(13.09)\end{array}$ & $\begin{array}{r}4.43 \\
(8.77)\end{array}$ & $\begin{array}{r}8.05 \\
(16.93)\end{array}$ \\
\hline & $\begin{array}{l}\text { Mean total call } \\
\text { volume Minutes / } \\
\text { person / week (SD) }\end{array}$ & $\begin{array}{r}42.63 \\
(88.13)\end{array}$ & $\begin{array}{r}15.42 \\
(25.68)\end{array}$ & $\begin{array}{r}2.53 \\
(2.59)\end{array}$ & $\begin{array}{l}22.67 \\
(35.5)\end{array}$ \\
\hline $\begin{array}{l}\text { Within Australia } \\
\text { Extra group } \\
\text { Community Calls }\end{array}$ & $\begin{array}{l}\text { Mean Individual Call } \\
\text { Length in Minutes } \\
\text { (SD }\end{array}$ & $\begin{array}{l}3.64 \\
(9.1)\end{array}$ & $\begin{array}{l}0.93 \\
(0.9)\end{array}$ & $\begin{array}{r}2.83 \\
(7)\end{array}$ & $\begin{array}{r}4.75 \\
(11.82)\end{array}$ \\
\hline
\end{tabular}




\begin{tabular}{|c|c|c|c|c|c|}
\hline & $\begin{array}{l}\text { Mean total call } \\
\text { volume Minutes / } \\
\text { person / week (SD) }\end{array}$ & $\begin{array}{r}10.78 \\
(15.57)\end{array}$ & $\begin{array}{r}1.29 \\
(1.5)\end{array}$ & $\begin{array}{r}10.47 \\
(13.78 \\
)\end{array}$ & $\begin{array}{r}15.02 \\
(27.28)\end{array}$ \\
\hline \multirow[t]{2}{*}{$\begin{array}{l}\text { Within Australia } \\
\text { Institutional Calls }\end{array}$} & $\begin{array}{l}\text { Mean Individual Call } \\
\text { Length in Minutes } \\
(\mathrm{SD}\end{array}$ & $\begin{array}{r}0.99 \\
(1.72)\end{array}$ & $\begin{array}{r}0.96 \\
(0.93)\end{array}$ & $\begin{array}{r}4.61 \\
(9.37)\end{array}$ & $\begin{array}{r}2.82 \\
(7.02)\end{array}$ \\
\hline & $\begin{array}{l}\text { Mean total call } \\
\text { volume Minutes / } \\
\text { person / week (SD) }\end{array}$ & $\begin{array}{r}0.27 \\
(0.27)\end{array}$ & $\begin{array}{r}0.28 \\
(0.59)\end{array}$ & $\begin{array}{r}0.88 \\
(1.92)\end{array}$ & $\begin{array}{r}1.31 \\
(2.43)\end{array}$ \\
\hline \multirow{2}{*}{$\begin{array}{l}\text { Strong Intragroup } \\
\text { Connections } \\
\text { (Numbers a } \\
\text { person called } \\
\text { more than } 12 \\
\text { times / year) }\end{array}$} & $\begin{array}{l}\text { Mean number of } \\
\text { Strong Connections / } \\
\text { Person (SD) }\end{array}$ & $\begin{array}{r}5.64 \\
(3.92)\end{array}$ & $\begin{array}{r}4.29 \\
(2.64)\end{array}$ & $\begin{array}{r}2.74 \\
(1.28)\end{array}$ & $\begin{array}{l}10.73 \\
(5.42)\end{array}$ \\
\hline & $\begin{array}{l}\text { Mean } \% \text { of group to } \\
\text { which member } \\
\text { strongly connected }\end{array}$ & $23 \%$ & $39 \%$ & $9 \%$ & $24 \%$ \\
\hline \multicolumn{2}{|c|}{$\begin{array}{l}\text { Estimated Value to Participants- Mean } \\
\text { total call value / person / year \$AUD } \\
\text { (SD) }\end{array}$} & $\begin{array}{r}3396 \\
(3089)\end{array}$ & $\begin{array}{r}680 \\
(682)\end{array}$ & $\begin{array}{r}961 \\
(1079)\end{array}$ & $\begin{array}{r}4859 \\
(4770)\end{array}$ \\
\hline
\end{tabular}

\section{Pre-existing community resources}

The intervention resources leveraged and strengthened pre-existing community resources, the most important being social capital. Three of the four communities had high existing social capital, as evidenced by the strong and wide pre-existing intragroup relationships, shown through the call volumes in Table 2.

Another resource was the women's familiarity with and propensity to use mobile phones. Prior to program commencement, the Nuer, B1 and Dari groups had wide mobile phone ownership, and this translated into high phone usage, as seen in Table 2. This demand was driven by a need for support and information.

When I first arrived I couldn't write, I couldn't speak and I was not familiar with all the places. And I was desperately waiting for someone to help me. (Mariam, Dari)

Participants reported how previous information deficit had caused problems such as credit card misuse, missed appointments, inappropriate purchases (including mobile phone services), inability to use public transport, and feelings of being unsafe when leaving home. This lack of and need for information enhanced the intervention by driving phone use, with resultant social connection benefits. 


\section{Resource organisation}

The above resources led to a cascade of resource reorganisation. For example, Myint Thin reported that, because of the intragroup contact, there was social contagion of the value of education, (a driver's license), which led to reorganisation of family automobile resources, giving an outcome of geographic freedom and increased knowledge of local geography.

Easy to contact, that's why our life is very improved. ... If we compare last year and this year ... we got this phone, and then we contact each other... And then we know so many places and we can go everywhere now. ... Can go more places. ... last year we not know many places, just we stay home. (Myint Thin, B2)

Mariam (Dari) summarised the effect of increased information that arose from attending the peer support groups:

We have got ... lots of information ... you get more information when you are in contact with other people. ... Yeah, we know from each other, we learn from each other... For example, we learn from other people, they share they experiences - what is expected in Australia, what is not. Some things we were not aware.

There were several general effects of this increase in information and support. Firstly, information led to more peer interaction; for example, information about community events led to increased participation. Secondly, increased communication, combined with increased trust, led to more sharing of emotional state, and this in turn increased the amount of support given and received. Finally, there was a widely reported increase in confidence that came from knowing that information was always available, due to mobile phone's 'anywhere, anytime' functionality.

One previous problem the women reported was a shortage of time (compounded by other resource deficits). For example:

[before the program] I did lots of shopping and I couldn't carry it. ... I didn't have any phone. ... It took me ... three hours to wait for someone to come and help me. [now] ... when I go shopping, I am not able to carry all these things. So I call my family and someone comes and help me with the shopping. (Fazel, Dari)

This temporal resource deficit caused stress.

They worry about it. It was very stress because sometimes my phone doesn't work or doesn't have any money. When you have an appointment and you stuck in the traffic you worry about you miss the appointment or you coming late, you know. (Nagat, Dari)

In this setting, an always-available mobile phone, backed by a supportive community, was useful because it helped to organise the women's physical and social systems. Many women reported how the phone allowed them to make better use of their own and 
other's time, because it enabled them to request help. They could take on more tasks in a day, because the communication made them more efficient and lessened the effects of running late, for example, by enabling request of emergency childcare. They could also synchronize with others, for example, by calling when shopping is done, instead of making drivers wait.

I know that I have appointment, or I need something, whether its doctor or Centrelink, so I will organise myself. More than last year, because of this phone. So I'm more organised than last year. (Lina, Nuer)

On an economic level, the program directly changed economic resource allocation, because the women did not allocate family funds for their own mobile phone resource. Almost every interviewee remarked on this.

When we need [help from other participants] just call them. We don't need to worry that my phone doesn't have any money ... I'm really happy with that. Because when I need them, or they need me they call me. (Nagat, Dari)

The program also had indirect economic effects, as women reported taking greater control of family resource organisation. The mobile phone gave the women control of their time and wider access to information, which made them more powerful and efficacious. For example, as news of sales at local shops spread through communities, the women organised group shopping trips that invited savings and gave them increased control of their financial allocations.

\section{Social processes}

Changes in social processes were clearly seen. The move to Australia itself caused great change in the women's social processes.

In Burma all the neighbours, we know each other, talk to each other, ... you must know everybody but here nobody knows each other. (Lah Win, B1)

Australia was often an isolating, disempowering environment for participants, and the women expressed demand for improved social processes. The phone-facilitated communication allowed the women to express their human resource potential, by facilitating participation in social processes. This was summarised by an elderly woman, who bemoaned her previous inability to contribute:

In my culture being an elder, you have alot of duties... and according to my age I would intervene and try to counsel [couples in difficulty]... now because I have this telephone if I come across a relationship issue... so my advice would be like this ... because of this telephone ... these are the kind of things that I talk about. (Nyibol, Nuer)

The help provided to each other was not only practical. The refugee experience was often traumatic, and the program provided a space where the women could share their personal refugee experience, socially validate what they were feeling, and provide an 
audience for their peers. An oft reported sentiment was the ability to get social support and advice, especially by the single mothers. Nyibol reports:

We the single parents who are looking after many children ... It is very very very challenging and a lot of difficulties that we are facing ... if we live here with our husbands, you know, we wouldn't have all these responsibilities that we talk about, you know. We will share the responsibilities, bringing up the children, you know, with them. ... So what you do? You call your friend. ... if you talk to them ..., it will shift your thinking about all these flaws and anxieties ... It give you love and warmth when you are talking to that person. (Nyibol, Nuer)

This dynamic decreased isolation, as the following quotes demonstrate:

Before, I was sick, I don't have much contact with outsiders, but now with phone, I got to know more people, share more friendship, I will go out more. (Lah Win, B1)

When you are worried and there is no person that you can talk about what worries you, it is very hard. But since I have this [phone], even though my accommodation situation haven't change, I'm always with my friends talking about different things and we laugh. And so its changed my life because I think: why should I feel stuck in this small house with the children? So I don't think about this every time. (Rita, Nuer)

\section{Settings outcomes}

At a settings level, one reported outcome was increased efficiency of a traditional female task, shopping. This change was effected through a variety of methods, such as increased knowledge of current bargains, reminders of necessary seasonal purchases (e.g. school supplies), and by making shopping social, using the phone to coordinate group trips.

In the following quote, Myint Thin discusses the shopping related effect of increased information on a group member who formerly did not go out much.

[it was] Very bad [for her before] and very improved for her now. Before, when she doesn't have the phone, how can she know [how to go to different places]? ... She just stay at home, now she know it, and then sometimes her husband doesn't send to the shop, she has to walk. ... She go out often. Sometimes we rang her, where are you? She is at the shopping centre, she's not at home. ... now she [does house chores] very fast. Go out. Go out. (Myint Thin, B2)

Of wider ramification was the increase in mobility. First, the women felt better about leaving home, because they felt safer when out, and they felt better about leaving their children at home because they could call home anytime for free. Too, it became physically easier to leave home, due to an increased ability to coordinate lifts and to use 
public transport, the latter due to their new facility to get information from a heritage language peer.

I feel more confident after having this phone. Now I go to the shops, and I go to my friend's house. Anywhere I go I feel safe, that's why I can contact them. And I contact my family and ask them how they are going. It makes me more confident. (Fazel, B2)

Education, from micro-education related information transfer about daily living in Australia to formal education like driver training, sewing classes and family day care training, was a common outcome. Course information spread across communities, leading to powerful peer effects.

They are also now, most of our friends they also driving. They watch out each other, our community are watch out each other. Is someone doing something that improving, and driving, you would like to drive also? And they trying hard. So many people can drive now. (Myint Thin, B2)

One year after program completion, the Nuer leader reported that $95 \%$ of the Nuer women in the program were employed, compared to $9 \%$ at program start. The majority had completed the family day care training course, which demonstrates the peer effects.

Health outcomes resulted from both the increased coordination, and the doctor-onspeed-dial phone functionality. This facilitated making and attending appointments for the women and their families. More importantly, the program had psychological and physical health benefits.

I feel much relieved and relax ... because of the phone. Even when I went for a walk ... to avoid getting bored, I used to call my friend and walk and talk. (Farhana, Dari)

The experiences engendered by the program led to the women having greatly increased personal power, and this empowerment took hold in other parts of their lives. Myint Thin (B2) talked about how the phones were useful in interrupting domestic violence in their community.

If [husbands] angry sometimes they would like to beat the wife. Now we have the phone can you beat? We have the phone we can calling [the police].

She explained further, detailing how increased information both helped lives, and flowed through the community:

Before, [husbands] take all of the money. And then what we need we have to ask from him. Anything else we would like to buy we have to ask from him. He keep it all, the money ... So later on we have the phone, we know it. And also our case co-ordinator explain it. And then our chance. Women also have to be a chance,... We know its our chance, and then we tell them.... And when we tell them, they angry. And then they kick [us]. We call the police. We call the police they afraid and later on the kicking stopped. 
The changes to social processes and outcomes were strengthened and integrated into the community structure through positive feedback loops. Many women mentioned that phone usage led to stronger relationships and increased trust:

[the phone] is strengthening my relationship with the people that are my close relatives because especially, you know, each day in the morning or whenever I have time I call them, "how are you?" and "how are the kids this morning?" (Wilma, Nuer)

Rozilah (B2) gave us a simple example, describing how the phone made it easier to go out, which led to better English, which in turn would make it easier to go out:

... before I do not go anywhere, I just stay at home. I don't want to be housebound but I want to go out ... since I've got the phone, I can contact [my friends] to come and pick me up anytime ... Compared to last year, there is some improvement in my English. Because I've been going around so I get to know the English language a bit more.

\section{Followup}

Although we did not formally follow up participants, DW and LK had extensive contact with Nuer and B1 group leaders. The Nuer group leader stated that one year after the program termination, most participants had undergone training, and all but one were employed. Similar changes were reported by the B1 leader. Participants were reported to be both much busier and richer.

Both leaders reported greatly increased mobile phone communication and community knowledge of mobile phone resources. This allows them to take advantage of the fluid mobile phone market, where there is now similar commercial plans available (eg unlimited free intragroup calling). Many participants had increased digital literacy, and have organised unlimited intragroup and low cost overseas calling, often through the use of multiple mobile phone handsets to access various service providers.

We had less contact with the B2 and Dari communities post intervention, but some indication of outcome can be derived from the post intervention interviews. B2 group was likely to continue accumulating social capital, due the majority of group members moving to the same street by program end. The Dari group was less likely to remain well connected.

\section{Discussion}

Viewed through Tseng and Seidman's framework (2007), the intervention consisted of two interlinked communication resources: peer support training and mobile phone calling. The former was designed to actively affect social processes by developing and strengthening relationships, hence providing a more fertile ground for the phones. The phone resource was a more passive intervention on social processes, because of social processes demand 'actions and operations' (Kelly et al, 2000:139). To affect social processes, phones need to be used, and phone use is facilitated by trust, relationships, 
interdependence, desire to communicate, and mobile phone familiarity. The call volumes and breadth, seen from the program start, indicate that these features existed in the community, in various forms, prior to program commencement.

Once used, the phones provided more than just networking. They provided "a social amenity" (Goodman, 2005), unlocking both personal resource potential (Kelly 2000), as seen in the women's ability to give and receive information and physical, economic, social and emotional support, and community resource potential, through modifying norms around individual development, such as the value of both education and relationships with other social systems.

Information transfer is often mentioned as a feature of mobile phones (Kyem \& LeMaire, 2006), and in these communities, this was particularly the case. Although each woman lacked specific information, the community as a whole often did not. Each refugee had learned a set of practical skills around living in Australia, and as a group, were themselves an underutilised settlement information resource. The program exploited the imbalance between the wealth of community information and the individual lack of information, providing community access to each woman's accrued information.

Free mobile calling allowed good ideas to flow through the community. Furthermore, this free flow of communication and information allowed the women to better organise their own and other's resources, leading to more efficient resource utilisation in areas such as time, knowledge, money, and transport.

Prior to the intervention, this was less prevalent, due to structural factors. As David (2013) contends, internalised sexism and racism had led the women into a selfperpetuating situation of not allocating resources to themselves since they did not perceive themselves as a resource. The B2 group demonstrated this most clearly; at program commencement, when asked about pre-existing mobiles, they were mostly incredulous, saying "why would I need a mobile?". This is tragic, but also for the intervention, an opportunity. Because of this devaluing, the women had other underutilised personal resources, such as their time and their social capital.

Prior to the program, economic factors did impede participants from using their communication resources. There are competing demands, especially due to their place at the center of families. That said, mobile phone cost varies with usage and consumer economic literacy, ranging from $\$ 0.83 /$ month, a not insurmountable sum. This intervention gave knowledge and experience, which allowed the women to better judge the value of mobile cost in their ongoing budgets, by providing them with some indication of potential value. It also jumpstarted the community conversation around mobiles, greatly increasing community knowledge and power vis-a-vis mobile consumption.

The phones allowed the women to participate in community life, and through participation they learned societally fruitful roles, norms and practices, developing their shared social system resources (Kelly, 2000). As the program progressed, social norms 
changed, for example, norms around going out of the home, control of family money, and ability to work outside the home. This norm change was supported by various communication pathways such as phone calls between individuals, and shared group stories.

Phone use increased social capital accumulation, and the ease of communication made existing social capital more usable. At the relationship level, stronger relationships made it easier to use the phone as well as ask more of one's relationships. The interlinked nature of our theoretical framework was demonstrated, in that social processes not only directly affected the women's ability to make resource organisation decisions but also indirectly affected resource availability itself (Tseng and Seidman, 2007). The latter is because these social processes improved information availability which ameliorated the women's key deficits, such as information, mobility, and Australian societal engagement. This increase in social capital value and stature also increased the community's perception of women's value, as social capital is often seen as a component of a “women's way of knowing” (Belenky, 1997).

\section{Limitations and future work}

The uniqueness of the Dari group call pattern points to an obvious truth, that it takes social capital to make social capital. Where the relationships did not exist prior to the program, the intragroup calling functionality was not as useful. The peer support training, despite being praised by Dari interviewees as a valuable social experience, did not substitute for pre-existing relationships with respect to intragroup calling volumes.

Future programs or interventions of this nature should focus on either recruitment of groups with existing strong relationships (e.g. snowball recruitment), or prioritise relationship-building. Similarly, the program works best in communities accustomed to doing things communally, relying on each other, and possess a willingness to help, and to be helped by others.

Phone calls, as used by this cohort, is synchronous communication, yet there is advantage in being able to communicate asynchronously, e.g. through text messages. Asynchronous text-based communication was problematic due to the women's lack of literacy and/or the inability of mass market phones to represent heritage language characters. Access to such communication pathways would enhance and also allow oneto-many communication. Future work should consider asynchronous communication methods, such as text-based communication, discussion groups, or even voice messaging applications.

\section{Conclusion}

Non-dominant cultures (e.g. women and traditional) place much value on relationships, and strong relationships can make good use of communication technologies. This project shows the value of these cultural traits, because it allows participants to demonstrate the strengths of such knowledge in a technologically enhanced setting, leading to distributed, empowerment-based information sharing. 
As evidenced by the phone call logs, refugee women have huge unmet need for communication resources, related to a need for information and support apropos life in Australian society. The program targeted this expressed community need. It took advantage of these local conditions, subsidised resources appropriate to satisfy the need, and allowed the resources themselves to exert powerful direct and indirect effects on social processes.

While we do not believe that this intervention is a panacea for underprivileged groups, it does work very well for communities with specific characteristics, such as an ability to make use of social capital and underutilised social resources.

Our research demonstrates the value of information for marginalised peoples, and the usefulness of technology to help provide that information. It shows how, given appropriate circumstances, there can be abundant resource in the refugee community, due to appropriate relationships and ability to use. While these circumstances are supported by some government policies such as family resettlement, reunification and sponsorship, other policies, such as housing policies that promote geographic isolation, do not. There should be more policy cognizance of the potential value of helpful relationships in refugee resettlement. We recommend that communities with these characteristics be provided with communication resources to enable them to make the best use of their own resources. 


\section{Acknowledgments}

We acknowledge the support of VicHealth for funding for this project.

\section{References}

Australian Bureau of Statistics (ABS). (1999). The information society and the information economy in Australia. Retrieved July 2, 2015, from http://www.abs.gov.au/ausstats/ abs@.nsf/featurearticlesbytitle/485FD68C254FD5EECA2569DE0028DE90? OpenDocument

Beadle, S. (2014). Facilitating the Transition to Employment for Refugee Young People (Report). Centre for Multicultural Youth. Retrieved from http://minervaaccess.unimelb.edu.au/handle/11343/45124

Belenky, M. F., Clinchy, B. M., Goldberger, N. R., \& Tarule, J. M. (1997). Women's Ways Of Knowing: The Development Of Self, Voice, And Mind 10th Anniversary Edition (10 Anv edition). New York: Basic Books.

Cislo, A. M., Spence, N. J., \& Gayman, M. D. (2010). Mental Health and Psychosocial Adjustment of Cuban Immigrants in South Florida. Social Science \& Medicine, 71(6), 1173-1181. http://doi.org/10.1016/j.socscimed.2010.06.001

Correa-Velez, I., Gifford, S. M., \& Barnett, A. G. (2010). Longing to belong: social inclusion and wellbeing among youth with refugee backgrounds in the first three years in Melbourne, Australia. Social Science \& Medicine, 71(8), 1399-1408. http://doi.org/ $\underline{10.1016 / j . s o c s c i m e d .2010 .07 .018}$

David, E. J. R. (2013). Internalized Oppression: The Psychology of Marginalized Groups (1st ed.). New York: Springer Publishing Company.

Dow, H. D. (2011). An Overview of Stressors Faced by Immigrants and Refugees: A Guide for Mental Health Practitioners. Home Health Care Management \& Practice, 23(3), 210217. http://doi.org/10.1177/1084822310390878

Fisher, K. E., Durrance, J. C., \& Hinton, M. B. (2004). Information grounds and the use of need-based services by immigrants in Queens, New York: A context-based, outcome evaluation approach. Journal of the American Society for Information Science and Technology, 55(8), 754-766. http://doi.org/10.1002/asi.20019

Foster-Fishman, P. G., Nowell, B., \& Yang, H. (2007). Putting the system back into systems change: a framework for understanding and changing organizational and community systems. American Journal of Community Psychology, 39(3-4), 197-215. http://doi.org/ 10.1007/s10464-007-9109-0

Goodkind, J. R., \& Deacon, Z. (2004). Methodological issues in conducting research with refugee women: Principles for recognizing and re-centering the multiply marginalized. Journal of Community Psychology, 32(6), 721-739. http://doi.org/10.1002/jcop.20029

Goodman, D. (2005). Linking mobile phone ownership and use to social capital in rural South Africa and Tanzania. INTERMEDIA-LONDON, 33(4), 26.

Kelly, J. G., Ryan, A. M., Altman, B. E., \& Stelzner, S. P. (2000). Understanding and Changing Social Systems. In J. Rappaport \& E. Seidman (Eds.), Handbook of Community Psychology (pp. 133-159). Springer US.

Kyem, P. A. K., \& LeMaire, P. K. (2006). Transforming recent gains in the digital divide into digital opportunities: Africa and the boom in mobile phone subscription. The Electronic 
Journal of Information Systems in Developing Countries, 28. Retrieved from http:// www.ejisdc.org/ojs2./index.php/ejisdc/article/view/343

Liamputtong, P. (2013). Qualitative Research Methods, Fourth Edition (4 edition). Australia: Oxford University Press.

Liamputtong, P., Koh, L., Wollersheim, D., \& Walker, R. (2015). Peer support groups, mobile phones and refugee women in Melbourne. Health Promotion International, dav015. https://doi.org/10.1093/heapro/dav015

Ngum Chi Watts, M. C., Liamputtong, P., \& Carolan, M. (2014). Contraception knowledge and attitudes: truths and myths among African Australian teenage mothers in Greater Melbourne, Australia. Journal of Clinical Nursing, 23(15-16), 2131-2141. http:// doi.org/10.1111/jocn.12335

Rappaport, J. (1987). Terms of empowerment/exemplars of prevention: Toward a theory for community psychology. American Journal of Community Psychology, 15(2), 121-148.

Schweitzer, R., Melville, F., Steel, Z., \& Lacherez, P. (2006). Trauma, post-migration living difficulties, and social support as predictors of psychological adjustment in resettled Sudanese refugees. Australian and New Zealand Journal of Psychiatry, 40(2), 179-188.

Smith, E. J. (2006). The Strength-Based Counseling Model. The Counseling Psychologist, 34(1), 13 -79. http://doi.org/10.1177/0011000005277018

Stewart, M., Dennis, C. L., Kariwo, M., Kushner, K. E., Letourneau, N., Makumbe, K., Makwarimba, E., Shizha, E. (2015). Challenges Faced by Refugee New Parents from Africa in Canada. Journal of Immigrant and Minority Health, 17(4), 1146-1156. http:// doi.org/10.1007/s10903-014-0062-3

Tempany, M. (2009). What Research tells us about the Mental Health and Psychosocial Wellbeing of Sudanese Refugees: A Literature Review. Transcultural Psychiatry, 46(2), $300-315$. http://doi.org/10.1177/1363461509105820

Triandis, H. C. (1996). The psychological measurement of cultural syndromes. American Psychologist, 51(4), 407-415. http://doi.org/10.1037/0003-066X.51.4.407

Tseng, V., \& Seidman, E. (2007). A systems framework for understanding social settings. American Journal of Community Psychology, 39(3-4), 217-228. http://doi.org/10.1007/ $\underline{\mathrm{s} 10464-007-9101-8}$ 